\title{
THE INFLUENCE OF INDIVIDUAL AND REGIONAL FACTORS ON ASSOCIATION BETWEEN LEISURE TIME PHYSICAL ACTIVITY AND PSYCHOLOGICAL COMPLAINTS AMONG ADOLESCENTS IN EUROPE
}

\author{
Gintare Petronyte, Apolinaras Zaborskis \\ Institute for Biomedical Research, Kaunas University of Medicine, Kaunas, Lithuania
}

\begin{abstract}
SUMMARY
The aim of this study was to examine the association between leisure time physical activity and psychological complaints among adolescents and to determine to what extent this association is mediated by individual and regional factors. Data from the 2005/06 Health Behaviour in School-aged children (HBSC) survey, composed of 106,319 respondents aged 11, 13 and 15 from 20 European countries was analysed. Multilevel modeling showed that individual factors (gender, age and family socioeconomic status) were significant mediators of the association between leisure time physical activity and psychological complaints. The mediating effect of individual factors differed in the magnitude of the association. Regional differences in this association were not found. The findings suggest that individual factors contribute in explaining the association between leisure time physical activity and psychological complaints among adolescents. Future research should examine country specific characteristics which may influence this association.
\end{abstract}

Key words: physical activity, psychological complaints, adolescents, European countries

Address for correspondence: Gintare Petronyte, Institute for Biomedical Research, Kaunas University of Medicine, Eiveniu 4, LT - 50009, Kaunas -7, Lithuania. E-mail: gintare888@yahoo.com

\section{INTRODUCTION}

There is growing concern about mental health problems among adolescents (1). Epidemiological studies evaluating depression among adolescents report different prevalence rates, however, these studies generally stress that adolescents not only experience the whole spectrum of symptoms but also suffer from the significant morbidity and mortality associated with them $(2,3)$. Depression has been identified as the major risk for suicidal ideation, suicide attempts and completed suicide $(4,5,6)$. Suicide in adolescents is a major social and health problem worldwide $(7,8)$.

The fact that emotional and behavioural disorders are common and cause significant impairment enhances the importance of knowledge about protective factors in relation to these problems. The positive effect of exercise on depression in adults has been the subject of research for several decades (9). However, a recent review of the effectiveness of exercise-based intervention has hinted a lack of high quality trials demonstrating the positive effect of exercise in reducing anxiety and depression in children and adolescents (10).

Most of cross-sectional studies in adolescents reporting mental health effects of physical activity, particularly its frequency and duration, deal with the association between physical activity and various mental health aspects (11-14). Recent longitudinal studies provide stronger evidence for the association between physical activity and mental health, including emotional symptoms, prosocial behaviour and conduct problems $(15,16)$.

In Europe, data of the WHO study of Health Behaviour in School-aged Children (HBSC) provide comparative insights in some aspects of mental health and physical activity. Based on the international database of this study, our aim was to examine the association between leisure time physical activity and psychological complaints among adolescents and determine to what extent this association is mediated by individual and regional factors. At individual level, sociodemographic characteristics such as gender, age and socioeconomic status are found to be some of the most important predictors of health (17). The association between physical activity and psychological complaints can be hypothesized to be explained by these characteristics, however, it remains unclear which individual factor is the strongest predictor of the association between these constructs. The data used in this study also allow us to examine the extent to which these associations vary among regions within the European countries. It was hypothesized that regional differences may contribute in explaining the association between physical activity and psychological complaints. Previous studies, however, have ignored the importance of regional factor. An understanding of this association is essential to the development of intervention programmes that promote adolescent psychological well-being. 


\section{MATERIALS AND METHODS}

Data were obtained from the Health Behaviour in School-aged Children (HBSC) study, a cross-national survey supported by the World Health Organization for Europe, carried out in 2005/2006. The concept of the HBSC project has been described in detail elsewhere (18).

\section{Sample}

In all participating countries samples were designed to be nationally representative. The target population selected for sampling were students aged 11,13 and 15 . In each country the sample was based on a cluster design with the school class being the primary sampling unit. A minimum sample size for each country of approximately 4,500 was recommended, 1,500 from each age group. The present analysis is based on 106,319 (52,295 boys and 54,024 girls) students aged 11, 13 and 15 years from 20 European countries. In order to reflect regional homogeneity the countries were selected by geographical, cultural and economical criteria and classified into five groups. The selected countries representing the Europe's regions were: Northern European countries (NEC: Denmark, Norway, Sweden, Finland), Central European countries (CEC: the Czech Republic, Hungary, Slovenia, Croatia), Eastern European Countries (EEC: Estonia, Lithuania, Russia, Ukraine), Western European countries (WEC: Austria, Switzerland, France, Germany) and Southern European countries (SEC: Portugal, Spain, Italy, Greece).

\section{Instrument and Variables}

The study instrument was a standard questionnaire developed by the international research network. In all participating countries the final international version of the questionnaire was translated into their native language and piloted before conducting the survey. The data collection was carried out in accordance with research ethics principles.

\section{Psychological Symptoms}

Subjective health complaints were measured using the HBSC symptom checklist. The list includes four psychological symptoms (feeling low, irritability or bad mood, feeling nervous and sleeping difficulties). Students were asked how often they experienced these symptoms during the previous 6 months. Each complaint was rated on a five point scale: 'about every day', 'more than once a week', 'about every week', 'about every month', 'rarely or never'. In our study rankings were made on a 0-4 scale, where inexperience of a symptom was rated as 0 and experience every day rated as 4 .

\section{Physical Activity}

Leisure time physical activity was measured using the item "Outside school hours: how often do you usually exercise in free time so much that you get out of breath or sweat”? The response alternatives were: (1) 'every day', (2) '4-6 times a week', (3) '2-3 times a week', (4) ‘once a week', (5) ‘once a month' (6) 'less than once a month' and 'never'(7). In the analysis these responses were recoded into three groups according to physical activity frequency: '4-7 times a week' (responses 1 and 2), '1-3 times a week' (responses 3 and 4) and 'never' (responses 5, 6 and 7). The last group was used as the reference category.

\section{Family Affluence}

The Family Affluence Scale (FAS) was used as an alternative measure of parental socioeconomic status. This scale is based on four measures of material wealth (car ownership, bedroom sharing, holiday travel and computer ownership). Ordinal scoring from these measures was summed and then divided in a categorical variable indicating low, middle and high levels of FAS.

\section{Statistical Analysis}

Differences in prevalence of psychological complaints were tested using $\chi^{2}$ test. In order to better assess psychological complaints we combined all four items of psychological symptoms by the factor analysis. A single factor produced by principal component analysis was conducted on data. Positive factor score values on a single factor indicate a relatively high degree of psychological complaints versus negative values indicate a relatively low degree of psychological complaints. Two level models with student $(n=106,319)$ at level 1 and country $(n=20)$ at level 2, were fitted to examine the association between frequency leisure time physical activity and psychological complaints. The models were adjusted for age, gender, family affluence scale and region. Analyses were performed using SPSS 13.0 (SPSS Inc., Chicago, IL, USA) and MLwiN 2.02 (Institute of Education, University of London, London, UK).

\section{RESULTS}

\section{Descriptive Statistics}

Table 1 presents the prevalence of adolescents who reported experiencing psychological complaints by sociodemographic, physical activity and region variables. The prevalence of reported psychological complaints was higher in girls than in boys (49.5 vs $36.8 \%, \mathrm{p}<0.001)$. Psychological complaints significantly increased with age $(\mathrm{p}<0.001)$. Adolescents from families with low family affluence were more likely to report psychological complaints compared to middle and high (47.7\% vs $42.7 \%$ and $40.9 \%, \mathrm{p}<0.001)$. Adolescents who reported never being active in leisure time experienced more physiological complaints than their active counterparts $(\mathrm{p}<0.001)$. Regional differences in psychological complaints were observed $(p=0.01)$. The lowest prevalence of all complaints was observed in West Europe (42.6\%) while the highest prevalence rates of complaints were reported by adolescents from East Europe (44.1\%). 
Table 1. Percentage of adolescents reporting psychological complaints by sociodemographic characteristics, leisure time physical activity and region group.

\begin{tabular}{|c|c|c|c|c|c|}
\hline \multirow{2}{*}{ Variable } & \multirow{2}{*}{\multicolumn{2}{|c|}{ Category }} & \multicolumn{2}{|c|}{ Psychological complaints } & \multirow{2}{*}{ P-value } \\
\hline & & & $\mathrm{N}$ & $\%$ & \\
\hline Gender & \multicolumn{2}{|c|}{$\begin{array}{l}\text { boy } \\
\text { girl }\end{array}$} & $\begin{array}{l}19,260 \\
26,725\end{array}$ & $\begin{array}{l}36.8 \\
49.5\end{array}$ & $<0.001$ \\
\hline Age group & \multicolumn{2}{|c|}{$\begin{array}{l}11 \text { - year - old } \\
13 \text { - year - old } \\
15 \text { - year - old }\end{array}$} & $\begin{array}{l}12,564 \\
15,696 \\
17,531\end{array}$ & $\begin{array}{l}36.0 \\
44.1 \\
49.6\end{array}$ & $<0.001$ \\
\hline Family affluence & \multicolumn{2}{|c|}{$\begin{array}{l}\text { low } \\
\text { middle } \\
\text { high }\end{array}$} & $\begin{array}{l}10,811 \\
18,783 \\
15,058\end{array}$ & $\begin{array}{l}47.7 \\
42.7 \\
40.9\end{array}$ & $<0.001$ \\
\hline Leisure time physical activity & \multicolumn{2}{|c|}{$\begin{array}{c}\text { never } \\
\text { 1-3 times p/week } \\
4-7 \text { times p/week }\end{array}$} & $\begin{array}{c}8,089 \\
21,350 \\
15,801\end{array}$ & $\begin{array}{l}49.8 \\
43.9 \\
39.6\end{array}$ & $<0.001$ \\
\hline Region & $\begin{array}{l}\text { NEC } \\
\text { WEC } \\
\text { CEC } \\
\text { EEC } \\
\text { SEC }\end{array}$ & $\begin{array}{l}\text { North } \\
\text { West } \\
\text { Central } \\
\text { East } \\
\text { South }\end{array}$ & $\begin{array}{c}8,683 \\
10,169 \\
8,013 \\
10,328 \\
8,792\end{array}$ & $\begin{array}{l}43.2 \\
42.6 \\
43.5 \\
44.1 \\
42.9\end{array}$ & 0.011 \\
\hline
\end{tabular}

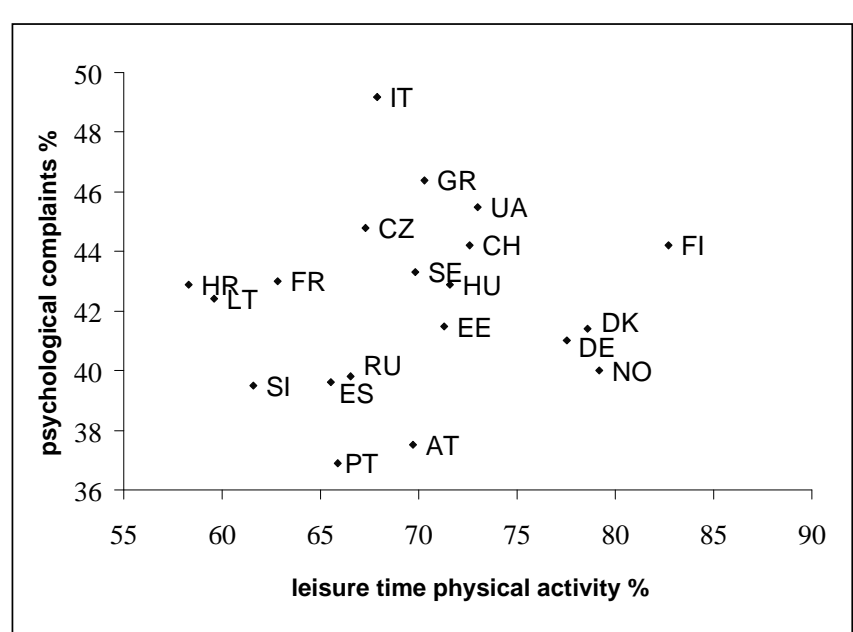

Fig 1. Associations between leisure time physical activity ( $x$ axis) and psychological complaints (y axis) in 20 European countries. Countries are referred to by 2-digit codes: $A T$ - Austria, FR - France, DE - Germany, CH - Switzerland, CZ - Czech Republic, HU - Hungary, SI - Slovenia, HR - Croatia, EE - Estonia, LT - Lithuania, RU - Russia, UA - Ukraine, ES - Spain, PT - Portugal, IT - Italy, GR - Greece, NO - Norway, SE - Sweden, FI - Finland, DK - Denmark.

\section{Association between Physical Activity and Psycho- logical Complaints in European Countries}

Fig. 1 shows a scatter plot of the associations between physical activity two and more times a week and psychological complaints in the European countries. It can be seen from the figure that some countries have relatively a high level of physical activity and a low prevalence of psychological complaints, while other countries tended to show the converse pattern.

\section{Influence of Factors on Association Between Physical Activity and Psychological Complaints}

Table 2 presents the results of the series of multilevel logistic regression analyses. The first model (Model 1 ) shows that leisure time physical activity was inversely associated with psychological complaints. Adolescents who were physically active 4-7 times a week were less likely $(\mathrm{OR}=1.54)$ to report psychological complaints. The association between leisure time physical activity and psychological complaints was significantly reduced after adjusting for gender (Model 2) and age (Model 3). Inclusion of family affluence scale in Model 4 again reduced the association between leisure time physical and psychological complaints. The strength of this association remained unchanged when the region group was added to the model (Model 5). Age and gender remained the strongest predictors with the odds ratio of 1.69 for girls and 1.82 for 15 -year-old adolescents in the final model with all mediators included.

\section{DISCUSSION}

The main aim of this study was to examine the association between leisure time physical activity and psychological complaints in nationally representative samples from 20 European countries. The hypothesized association between leisure time physical activity and psychological complaints was found in this study. Findings suggest that the higher the frequency of leisure time physical activity, the lower the risk of physiological complaints. Several hypotheses, including the social interaction, the distraction, as well as some physiological, have been proposed to explain the association between physical activity and mental health (19).

The present study focused on cross national variation in associations between physical activity patterns and health complaints. 
Table 2. Regression coefficients (standard errors in parentheses) for explanatory variables on association between leisure time physical activity and psychological complaints in multilevel logistic regression models

\begin{tabular}{|c|c|c|c|c|c|c|}
\hline \multirow{2}{*}{ Variable } & \multirow{2}{*}{ Category } & Model 1 & Model 2 & Model 3 & Model 4 & Model 5 \\
\hline & & B (SE) & B (SE) & B (SE) & B (SE) & B (SE) \\
\hline & intercept & $0.015(0.032)$ & $-0.311(0.033)$ & $-0.654(0.035)$ & $-0.530(0.036)$ & $-0.481(0.036)$ \\
\hline Leisure time physical activity & $\begin{array}{l}\text { 1-3 times /week } \\
4-7 \text { times /week }\end{array}$ & $\begin{array}{l}-0.251(0.018) \\
-0.432(0.019) \\
\end{array}$ & $\begin{array}{l}-0.205(0.019) \\
-0.300(0.019) \\
\end{array}$ & $\begin{array}{l}-0.185(0.019) \\
-0.237(0.020) \\
\end{array}$ & $\begin{array}{l}-0.165(0.019) \\
-0.216(0.020) \\
\end{array}$ & $\begin{array}{l}-0.165(0.019) \\
-0.216(0.020) \\
\end{array}$ \\
\hline Gender & girl & & $0.489(0.013)$ & $0.502(0.013)$ & $0.502(0.013)$ & $0.503(0.013)$ \\
\hline Age group & $\begin{array}{l}13 \text {-year-old } \\
15 \text {-year-old }\end{array}$ & & & $\begin{array}{l}0.339(0.016) \\
0.552(0.016)\end{array}$ & $\begin{array}{l}0.346(0.016) \\
0.559(0.016)\end{array}$ & $\begin{array}{l}0.346(0.016) \\
0.560(0.016)\end{array}$ \\
\hline Family affluence & $\begin{array}{l}\text { middle } \\
\text { high }\end{array}$ & & & & $\begin{array}{l}-0.173(0.017) \\
-0.213(0.019) \\
\end{array}$ & $\begin{array}{l}-0.173(0.017) \\
-0.215(0.019) \\
\end{array}$ \\
\hline Region & $\begin{array}{l}\text { WEC } \\
\text { CEC } \\
\text { EEC } \\
\text { SEC }\end{array}$ & & & & & $\begin{array}{l}-0.056(0.086) \\
-0.054(0.086) \\
-0.075(0.086) \\
-0.058(0.086)\end{array}$ \\
\hline
\end{tabular}

Model 1: physical activity only

Model 2: Model $1+$ gender

Model 3: Model $2+$ age

Model 4: Model $3+$ family affluence

Model 5: Model $4+$ region group

Note: reference category: leisure time physical activity once a month or less, boy, 11-year-old group, low family affluence, North region.

The key finding of our study was that Finland, Italy, Portugal and Austria substantially differed in the associations in comparison to other countries. The interpretation of the present finding is complicated due to the uncertainty of studies in this area. One possible explanation could be the sociocultural environment that contributes to the differences in these associations.

The observed differences in the associations between countries were not striking finding either theoretically nor empirically. The Eurobarometer survey has also identified a similar pattern and can provide some possibility for comparisons (20). Although comparisons are complicated due to different methodologies applied, we can find some similar trends in the results. According to the Eurobarometer survey, the association between physical activity and mental health was found in Finland, France, Germany, Spain and Sweden.

We also found that the association between leisure time physical activity and psychological complaints was mediated by individual factors. Being a girl and belonging to the older age group were found to be the significant mediators of this association. These findings are in line with the previous HBSC study reporting gender differences in health complaints and that these differences increasing with age (21). Family socioeconomic status was not the most important predictor of the association in the multilevel regression analysis, however, this finding contributes to the discussion about health inequalities in adolescents, particularly in health behaviour, which is relatively rarely examined $(22,23)$.

However, contrary to our hypothesis, we find no significant differences among the regions of the European countries in the association between leisure time physical activity and psychological complaints. When the region factor was added in the final model with all mediators, the strength of the association between leisure time physical activity and psychological complaints remained unchanged. This finding imply that the association we have reported may not be directly attributable to the region but possibly to other factors that were not examined in this study. One fruitful direction for future studies would be to investigate national differences in this association.

The interpretation of results of this study is restricted by several methodological limitations. Results were derived from a cross-sectional study design that does not allow us to draw conclusions on causality. This study relied on self-reported measures which might lead to potential bias. However, previous studies have shown that all measures used in our study are reliable and valid (23-25). The relatively weak association between leisure time physical activity and psychological complaints raise some questions. From a methodological viewpoint, the questionnaire questions have different time intervals (how often versus previous 6 months) we consider that this discrepancy could weaken this association substantially.

These limitations are balanced by several strengths. To our knowledge, this is the first study that examines the individual level factors in explaining the association between leisure time physical activity and psychological complaints. The second strength of the present study was that we used a large sample of countries that provide empirical evidence of cross-national variation in adolescent health. From a practical point of view, our results suggest that promoting leisure time physical activity could be important strategy in prevention psychological complaints.

In conclusion, the association between psychological complaints and leisure time physical activity is largely explained by individual level characteristics. Furthermore, this study fills an important gap about cross national differences and similarities in the examined association across Europe. Future research should examine country specific characteristics which may influence this association. Findings from such studies could guide policy that may have a substantial impact on health of adolescents. 


\section{Acknowledgment}

The Health Behaviour in School-aged Children Survey (HBSC) is an international study carried out in collaboration with WHO/EURO. The International Coordinator of the 2005/2006 study was Candace Currie (University of Edinburgh, Scotland) and the Data Bank Manager was Oddrun Samdal (University of Bergen, Norway). For details, see http://hbsc.org.

\section{REFERENCES}

1. Mental health: facing challenges, building solutions. Report from the WHO European Ministerial Conference. Copenhagen: WHO Regional Office for Europe; 2005.

2. Kessler RC, Avenevoli S, Ries Merikangas K. Mood disorders in children and adolescents: an epidemiologic perspective. Biol Psychiatry. 2001 Jun 15;49(12):1002-14.

3. Weller EB, Weller RA. Depression in adolescents growing pains or true morbidity? J Affect Disord. 2000 Dec;61 Suppl 1:S9-13.

4. Groholt B, Ekeberg O, Wichstrom L, Haldorsen T. Young suicide attempters: a comparison between a clinical and an epidemiological sample. J Am Acad Child Adolesc Psychiatry. 2000 Jul;39(7):868-75.

5. Stephen A, Leigh R, Graham M, Keeves J. Gender differences in the relationship between depression and suicidal ideation in young adolescents. Aust N Z J Psychiatry. 2001;35(4):498-503.

6. Chabrol H, Rodgers R, Rousseau A. Relations between suicidal ideation and dimensions of depressive symptoms in high-school students. $\mathrm{J}$ Adolesc. 2007 Aug;30(4):587-600.

7. Wasserman D, Cheng Q, Jiang GX. Global suicide rates among young people aged 15-19. World Psychiatry. 2005 Jun;4(2):114-20.

8. Hultén A, Jiang GX, Wasserman D, Hawton K, Hjelmeland H, DeLeo $\mathrm{D}$, et al. Repetition of attempted suicide among teenagers in Europe: frequency, timing and risk factors. Eur Child Adolesc Psychiatry. 2001 Sep;10(3):161-9.

9. Lawlor D, Campbell P. Exercise for depression. Cochrane Database Syst Rev. 2007;(2):CD004366.

10. Larun L, Nordheim LV, Ekeland E, Hagen KB, Heian F. Exercise in prevention and treatment of anxiety and depression among children and young people. Cochrane Database Syst Rev. 2006 Jul 19;(3): CD004691.

11. Brosnahan J, Steffen LM, Lytle L, Patterson J, Boostrom A. The relation between physical activity and mental health among Hispanic and non-Hispanic white adolescents. Arch Pediatr Adolesc Med. 2004 Aug;158(8):818-23.
12. Allison KR, Adlaf EM, Irving HM, Hatch JL, Smith TF, Dwyer JJ, et al. Relationship of vigorous physical activity to psychological distress among adolescents. J Adolesc Health. 2005 Aug;37(2):164-6.

13. Ussher MH, Owen CG, Cook DG, Whincup PH. The relationship between physical activity, sedentary behaviour and psychological wellbeing among adolescents. Soc Psychiatry Psychiatr Epidemiol. 2007 Oct;42(10):851-6.

14. Kantomaa MT, Tammelin TH, Ebeling HE, Taanila AM. Mental health and physical inactivity in Finnish youth aged 15-16 years. Med Sci Sports Exerc. 2007;39 Suppl 5:S48.

15. Motl RW, Birnbaum AS, Kubik MY, Dishman RK. Naturally occurring changes in physical activity are inversely related to depressive symptoms during early adolescence. Psychosom Med. 2004 May-Jun;66(3):33642.

16. Sagatun A, Søgaard AJ, Bjertness E, Selmer R, Heyerdahl S. The association between weekly hours of physical activity and mental health: a tree-year follow-up study of 15-16-year-old students in the city of Oslo, Norway. BMC Public Health. 2007 Jul 12;7:155.

17. Cockerham WC. Medical sociology. 8th ed. Upper Saddle River: Prentice Hall; 2001.

18. Roberts C, Currie C, Samdal O, Currie D, Smith R, Maes L. Measuring the health and health behaviours of adolescents through cross-national survey research: recent developments in the Health Behaviour in Schoolaged Children (HBSC) study. J Public Health. 2007 Jun;15(3):179-86.

19. Teychenne M, Ball K, Salmon J. Physical activity and likelihood of depression in adults: a review. Prev Med. 2008 May;46(5):397-411.

20. Abu-Omar K, Rütten A, Lehtinen V. Mental health and physical activity in the European Union. Soz Praventivmed. 2004;49(5):301-9.

21. Torsheim T, Ravens-Sieberer U, Hetland J, Välimaa R, Danielson M, Overpeck M. Cross-national variation of gender differences in adolescent subjective health in Europe and North America. Soc Sci Med. 2006 Feb;62(4):815-27.

22. Tuinstra J, Groothoff JW, van den Heuvel WJ, Post D. Social-economic differences in health risk behavior in adolescence: do they exist? Soc Sci Med. 1998 Jul;47(1):67-74.

23. Currie C, Molcho M, Boyce W, Holstein B, Torsheim T, Richter M. Researching health inequalities in adolescents: the development of the Health Behaviour in School-aged Children (HBSC) family affluence scale. Soc Sci Med. 2008;66(6):1429-36.

24. Booth ML, Okely AD, Chey T, Bauman A. The reliability and validity of the physical activity questions in the WHO health behaviour in schoolchildren (HBSC) survey: a population study. Br J Sports Med. 2001 Aug;35(4):263-67.

25. Haugland S, Wold B, Stevenson J, Aaroe LE, Woynarowska B. Subjective health complaints in adolescence. A cross-national comparison of prevalence and dimensionality. Eur J Public Health. 2001 Mar;11(1): 4-10.

Received January 30, 2009 Accepted in revised form April 23, 2009 